\title{
Consumption of dairy products and associations with incident diabetes, CHD and mortality in the Whitehall II study
}

\author{
Sabita S. Soedamah-Muthu ${ }^{1 *}$, Gabriel Masset $^{2}$, Lisa Verberne ${ }^{1}$, Johanna M. Geleijnse ${ }^{1}$ and \\ Eric J. Brunner ${ }^{2}$ \\ ${ }^{1}$ Division of Human Nutrition, Wageningen University and Research Centre, PO Box 8129, 6700 EV Wageningen, \\ The Netherlands \\ ${ }^{2}$ Department of Epidemiology and Public-Health, University College London, London, UK
}

(Submitted 22 June 2012 - Final revision received 7 March 2012 - Accepted 30 March 2012 - First published online 7 June 2012)

\begin{abstract}
Few prospective studies have examined the effects of different types of dairy food on the risks of type 2 diabetes, CHD and mortality. We examined whether intakes of total dairy, high-fat dairy, low-fat dairy, milk and fermented dairy products were related to these outcomes in the Whitehall II prospective cohort study. At baseline, dairy consumption was assessed by FFQ among 4526 subjects ( $72 \%$ men) with a mean age 56 (SD 6) years. Death certificates and medical records were used to ascertain CHD mortality and nonfatal myocardial infarction. Incident diabetes was detected by the oral glucose tolerance test or self-report. Incidence data were analysed using Cox proportional hazards models, adjusted for lifestyle and dietary factors. During approximately 10 years of follow-up, 273 diabetes, 323 CHD and 237 all-cause mortality cases occurred. In multivariable models, intakes of total dairy and types of dairy products were not significantly associated with incident diabetes or CHD (all $P$ values for trend $>0 \cdot 1$ ). Fermented dairy products was inversely associated with overall mortality (hazard ratios approximately 0.7 in the middle and highest tertiles; $P$ for trend $<0.01$ ) but not with incident CHD or diabetes $(P>0 \cdot 3)$. In conclusion, intakes of total dairy and types of dairy products showed no consistent relationship with incident diabetes, CHD or all-cause mortality.
\end{abstract}

Key words: Dairy products: Diabetes mellitus: Mortality: CHD: Nutrition: Prospective studies

Diabetes and CHD are both leading causes of hospitalisations, death and loss of disability-adjusted life years ${ }^{(1,2)}$. A considerable proportion of diabetes and $\mathrm{CHD}$ incidence can be prevented or delayed by healthy diet and exercise ${ }^{(3-6)}$. American and European dietary guidelines for CHD prevention recommend intake of low-fat dairy products ${ }^{(7,8)}$. Prospective cohort studies investigating the association between milk consumption and CHD have found conflicting results ${ }^{(9,10)}$. In a meta-analysis of nine prospective cohort studies, an inverse association between the highest relative to the lowest dairy product consumption and CHD was observed, with a relative risk of $0.92(95 \%$ CI $0.80,0.99)$, but milk was not analysed separately ${ }^{(9)}$. A recent dose-response meta-analysis pooling six prospective cohort studies did not show an association between milk consumption and CHD and all-cause mortality (relative risk 1.00 (95\% CI 0.96, 1.04) per $200 \mathrm{ml} \mathrm{milk)}{ }^{(10)}$. In this meta-analysis, data on dairy products other than milk in relation to CHD and all-cause mortality were not pooled because the number of studies was limited. For incident diabetes, several meta-analyses (summarising four to seven prospective cohort studies) reported statistically significant inverse associations with dairy consumption, especially lowfat dairy products ${ }^{(9,11,12)}$.

The largest studies in all these meta-analyses ${ }^{(9-12)}$ were from the USA ${ }^{(13-17)}$ with limited evidence coming from European studies. Early studies from the UK, the Caerphilly cohort study (baseline 1979-83) ${ }^{(18,19)}$, and the Oxford Vegetarian Study $(1973)^{(20)}$ only examined milk and other types of dairy food were not investigated in relation to diabetes, CHD or all-cause mortality. The aim of the present study was therefore to examine the relationship between different types of dairy food and incident type 2 diabetes, fatal and non-fatal CHD, and all-cause mortality using recent data from the Whitehall II study.

\section{Methods}

Study population

The Whitehall II cohort consists of London-based office staff working in twenty Civil Service departments during

Abbreviations: EI, energy intake; HR, hazard ratio; ICD, International Classification of Diseases. 
recruitment in 1985-8. The initial cohort consisted of 10308 civil servants (6895 men and 3413 women, aged 35-55 years), with a participation rate of $73 \%{ }^{(21)}$. During the follow-up, FFQ were completed at phase 3 (1991-3), phase 5 (1997-9), phase 7 (2003-4) and phase 9 (2007-9). As the FFQ-item format for milk intake was shown to be answered inconsistently at phase 3, the phase 5 FFQ (1997-9) was selected, completed by 5088 participants, as baseline for the present study. The study was conducted according to the guidelines laid down in the Declaration of Helsinki and all procedures involving human subjects were approved by the University College London Research Ethics Committee. Written informed consent was obtained from all subjects during each phase of the Whitehall II study.

\section{Assessment of dairy intake}

The FFQ comprised of 114 items. Breakfast cereals were assessed in a separate and open question, each participant being able to report up to two types of cereals. Milk consumption over the previous 12 months was assessed with two separate questions: first, on the type of milk most often used (full cream, semi-skimmed, skimmed, Channel Islands, dried, soya, other or none); second, on the usual daily amount (none, quarter of a pint, half a pint, three quarters of pint, one pint or more than one pint).

Consumption of other dairy products (single cream, double or clotted cream, yogurt, cheese, cottage or low-fat soft cheese, milk puddings, hot chocolate or Horlicks/Ovaltine) was reported in predefined frequency categories that ranged from never/less than once per month to six or more portions per $\mathrm{d}$. The FFQ was previously validated at phase 3 against a $7 \mathrm{~d}$ diary and blood biomarkers, although not for dairy products $^{(22)}$. For $\mathrm{Ca}$, energy-adjusted Spearman's correlations were 0.44 and 0.48 , for women and men, respectively.

In total, eight exposure variables were created for dairy consumption: total dairy (all dairy products, except butter and ice cream); high-fat dairy (full-fat cheese, yogurt, milk puddings, whole and Channel Islands milk); low-fat dairy (cottage cheese, semi-skimmed, skimmed milk and milk-based hot drinks); total milk (including whole and low-fat milk); lowfat milk (semi-skimmed and skimmed); fermented dairy (yogurt and total cheese); yogurt; total cheese (full-fat cheese and cottage cheese). Whole milk was consumed in too limited amounts to examine this separately. We were unable to distinguish types of yogurt intake as no information was available on sugar or fat content.

\section{Other measurements}

A self-completed questionnaire was used for several diagnoses (e.g. ever told by a doctor that they had angina, heart attack, hypertension or diabetes), exercise, diet, alcohol, smoking status and the last known civil service employment grade (six categories varying from highest employment grades defined as unified employment grades 1-6 according to salary scales, followed in descending order by senior, higher and executive officer, and clerical/support staff as the lowest employment grade). Participants subsequently attended a clinical examination to have a blood sample collected, blood pressure measured, and height and weight recorded. Blood pressure was measured twice in the sitting position after a 5 min rest using the Hawksley Random Zero Sphygmomanometer (Hawksley and Sons). Weight was measured using Soehnle electronic scales. BMI was calculated as weight divided by the square of height. Total cholesterol and TAG were determined from fasting serum samples with an Olympus Analyser (AU5200), whereas HDL-cholesterol was determined with the AU800 Olympus Analyser

\section{Outcomes}

Outcomes included incident diabetes and CHD collected up to December 2009 and all-cause mortality cases were collected up to January 2010. In total, 323 cases of fatal and non-fatal CHD, 237 all-cause deaths, and 273 cases of incident diabetes occurred during the follow-up period. Participants were flagged by the National Health Service Central Registry, who notified us of the date and cause of all deaths up to January 2010. Deaths were classified as coronary if 'International Classification of Diseases (ICD)', 9th edition codes 410-414 or ICD 10th edition codes I20-I25 were present on the death certificate. ICD-10 codes were I00-I99 for CVD mortality and C00-C97 for cancer mortality. Follow-up for mortality was essentially complete (99.9\% flagged at the National Health Service Central Registry).

Cases of non-fatal myocardial infarction were identified from twelve-lead electrocardiograms. In addition, questionnaire items on chest pain using the Rose questions ${ }^{(23)}$ and doctor's diagnosis of angina and myocardial infarction were used. Details of physician investigations, diagnoses and interventions were sought from medical records for all potential cases for final ascertainment. Classification, following the WHO Monitoring of Trends and Determinants in Cardiovascular disease methods, was carried out independently by two trained coders, with adjudication in the event of disagreement. Self-reported myocardial infarction in the absence of verification was not classified as myocardial infarction.

Incident cases of diabetes were identified by self-report of doctor's diagnosis, initiation of anti-diabetic medication (oral hypoglycaemic agents or insulin) and a $2 \mathrm{~h} 75 \mathrm{~g}$ oral glucose tolerance test at phases 5, 7 and 9, according to the 1999 WHO classification.

\section{Statistical methods}

Consumption of total dairy and dairy subgroups was adjusted for total energy intake (EI) according to the residual $\operatorname{method}^{(24)}$. For each exposure variable, residuals were obtained by the regression of EI from the selected dairy products $v$. total EI. Participants were then ranked in sex-specific tertiles according to their residual values. Tertiles were included in Cox proportional hazards regression models, the reference group being the tertile with the lowest intake for each exposure variable. Follow-up time in years was used as the time variable. Scaled Schoenfeld residuals were used to 
Table 1. Baseline characteristics within sex-specific tertiles of energy-adjusted total dairy intake (Mean values and standard deviations)

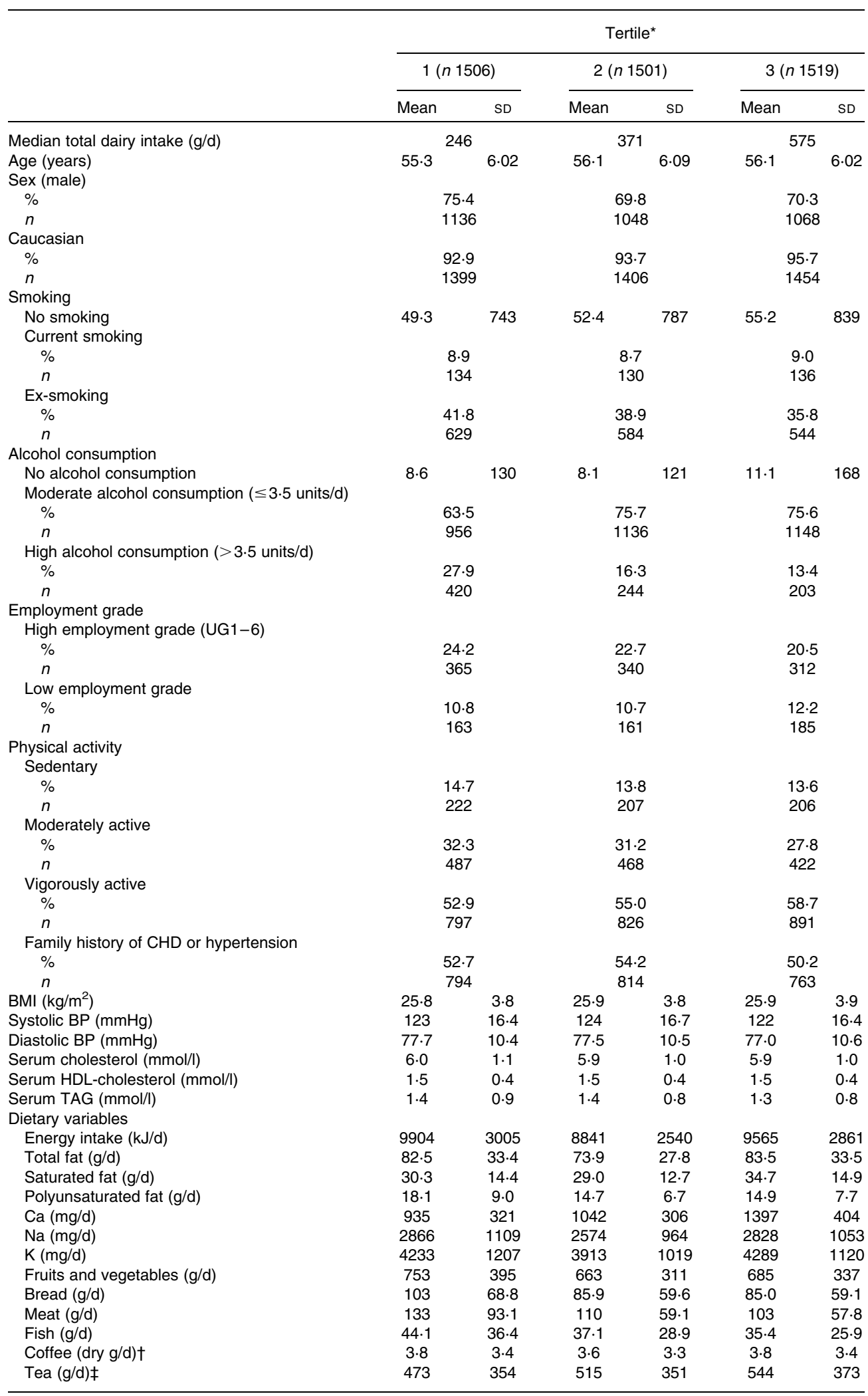

UG1-6, unified employment grades (code 1, highest salary; code 6, lowest salary); BP, blood pressure.

*Tertiles are sex-specific.

† Expressed as dry weight.

$\ddagger$ Expressed as consumed weight. 
test the proportional hazards assumption which was met for all models. Outcomes included incident cases only. Both linear and quadratic trends were examined with Cox proportional hazards regression models.

For each exposure-outcome combination, three models were run. In the first model, adjustments were made for age (continuous), ethnicity (white Caucasians as the reference group, south Asian, black and other ethnicity) and employment grade (high employment grade as the reference group). The second model additionally included smoking status (never smoking as the reference group, current and past), alcohol intake (no consumption as the reference group, moderate ( $\leq 3.5$ units/d) and high alcohol intake ( $>3.5$ units/d)), BMI (continuous), physical activity level (inactive as the reference group, moderately active and vigorously active) and family history of CHD or hypertension (yes/no). In the third model, further adjustments were made for intake of fruit, vegetables, bread, meat, fish, coffee, tea and total energy (all continuous). We additionally adjusted for BMI changes between phase 5 (1997-9) and phase 7 (2003-4) using the third model. Also, analyses were rerun to investigate the effect of energy misreporting. BMR was calculated using the 1991 Committee on Medical Aspects of Food Policy equations ${ }^{(25)}$. The ratio of the EI:BMR (EI:BMR) was then calculated for each individual. Participants with EI:BMR $<1.14$ were classified as 'energy under-reporters' based on the cut-off limits developed by Goldberg et al. ${ }^{(26,27)}$, whereas those with EI:BMR $>2 \cdot 24$ as over-reporters. Normal energy reporters were participants with $1 \cdot 14 \leq \mathrm{EI}: \mathrm{BMR} \leq 2 \cdot 24$.

To take the disparity in consumption levels across tertiles into account when comparing hazard ratios (HR) between dairy products, the HR per standard deviation unit were calculated.

Of the 5088 participants who completed the FFQ, ninetynine participants were excluded due to missing dairy intake information and 463 participants were excluded with missing values for confounders, leaving a sample of 4526 participants for complete case analysis. For the outcome response rates, there were 133 missing values for incident diabetes, eleven missing values for incident $\mathrm{CHD}$ and four missing values for all-cause mortality (in total, 4522 participants). For the analyses with incident diabetes, prevalent diabetes ( $n$ 207) cases were excluded, leaving 4186 participants for the diabetes analyses. For the analyses with incident $\mathrm{CHD}$, all prevalent CHD cases ( $n$ 260) were excluded, leaving 4255 participants for the CHD analyses.

\section{Results}

The characteristics of 4526 participants are shown by tertiles of energy-adjusted total dairy consumption in Table 1 . The mean age at baseline was 56 (SD 6.1) years, $72 \%$ were male and the mean BMI was 25.9 (SD 3.8$) \mathrm{kg} / \mathrm{m}^{2}$. The median total dairy consumption ranged from $246 \mathrm{~g} / \mathrm{d}$ in the first tertile to $575 \mathrm{~g} / \mathrm{d}$ in the third tertile. Overall, median intakes were $378 \mathrm{~g} / \mathrm{d}$ for total dairy, $73 \mathrm{~g} / \mathrm{d}$ for high-fat dairy, $294 \mathrm{~g} / \mathrm{d}$ for $l o w-f a t$ dairy, $294 \mathrm{ml} / \mathrm{d}$ for total milk, $41 \mathrm{~g} / \mathrm{d}$ for fermented dairy products, $21 \mathrm{~g} / \mathrm{d}$ for yogurt and $17 \mathrm{~g} / \mathrm{d}$ for cheese. Higher consumption of dairy products was significantly inversely associated with physical activity $(P=0.03)$, consumption of alcohol, bread, meat, fish and PUFA (all $P<0 \cdot 01$ ), and positively with ethnicity, tea, Ca and saturated fat (all $P<0 \cdot 01$ ).

\section{Type 2 diabetes}

A total of 4186 participants without prevalent diabetes were followed for 9.8 (SD 1.9) years. There were 273 incident type 2 diabetes cases available for complete case analysis. Uni- and multivariable Cox proportional hazards models for various dairy products and incident type 2 diabetes are presented in Table 2. In the final adjusted models, total dairy products were marginally positively, but not significantly, associated with incident type 2 diabetes with HR of 1.3 in the highest tertile. Intakes of high- and low-fat dairy, total milk, low-fat milk, fermented dairy products, yogurt and cheese were not associated with incident diabetes. Additional adjustments for changes in BMI during the follow-up did not alter any of the results for diabetes (data not shown).

\section{CHD}

A total of 4255 participants were followed for $10 \cdot 8$ (SD 2.6) years. There were 323 incident CHD cases available for complete case analysis. Intakes of total dairy, high-fat and low-fat dairy, total milk, low-fat milk, fermented dairy products, yogurt and cheese were not statistically significantly associated with incident CHD (Table 3). The majority of these dairy products (total dairy, low-fat dairy products, total milk, lowfat milk and cheese) were marginally inversely associated with incident CHD with HR between 0.8 and 0.9 in the final adjusted models. Additional adjustments for changes in BMI during the follow-up did not alter any of the results for CHD (data not shown).

\section{All-cause mortality}

A total of 4522 participants were followed for 11.7 (SD 1.5) years. There were 237 deaths available for complete case analysis. Total dairy consumption was non-linearly inversely associated with all-cause mortality ( $P$ for quadratic trend $=0 \cdot 008$; Table 4 ), with HR of 0.72 (95\% CI $0.52,0.99)$ in the highest tertile of model 3. No association with mortality was found for consumption of high- or low-fat dairy, with HR of 0.83 and 0.84 ( $P$ for trend $>0 \cdot 25$ ). There were no statistically significant associations of total milk $(\mathrm{HR}=0.89)$, low-fat milk $(\mathrm{HR}=0.82)$ and total cheese $(\mathrm{HR}=1 \cdot 00)$ with all-cause mortality.

Fermented dairy consumption was inversely associated with all-cause mortality with HR of 0.65 (95\% CI $0.47,0.90)$ in the highest tertile (model 3, $P$ for trend $<0 \cdot 01$ ). This association remained after adjustment for intake of other dairy products (HR 0.62, 95\% CI 0.44, 0.89 in the highest tertile of model 3; $P$ for trend=0.006). The association between fermented dairy consumption and all-cause mortality was also examined for yogurt and cheese separately, expressed as HR per SD unit (SD for cheese and yogurt were, respectively, 22.3 and $61.6 \mathrm{~g} / \mathrm{d}$ ). Cheese was not associated with all-cause 
Table 2. Association between dairy intake and the 10-year risk of diabetes in 4186 participants of the Whitehall II study (Hazard ratios and $95 \%$ confidence intervals)

\begin{tabular}{|c|c|c|c|c|c|c|}
\hline & \multicolumn{6}{|c|}{ Tertiles of sex- and energy-adjusted intake } \\
\hline & \multirow{2}{*}{$\frac{1}{\text { Hazard ratio }}$} & \multicolumn{2}{|c|}{2} & \multicolumn{2}{|c|}{3} & \multirow[b]{2}{*}{$P$ for trend } \\
\hline & & Hazard ratio & $95 \% \mathrm{Cl}$ & Hazard ratio & $95 \% \mathrm{Cl}$ & \\
\hline \multicolumn{7}{|l|}{ Total dairy } \\
\hline Median intake $(\mathrm{g} / \mathrm{d})$ & 246 & & 371 & & 575 & \\
\hline No. of subjects/cases & $1379 / 85$ & & $1403 / 95$ & & $1404 / 93$ & \\
\hline Model $1^{*}$ & Ref & $1 \cdot 10$ & $0.82,1.48$ & $1 \cdot 13$ & $0.84,1.51$ & 0.44 \\
\hline Model $2 \dagger$ & Ref & $1 \cdot 16$ & $0.86,1.56$ & 1.15 & $0.85,1.56$ & 0.36 \\
\hline Model 3‡ & Ref & $1 \cdot 24$ & $0.92,1.69$ & $1 \cdot 30$ & $0.95,1.77$ & 0.11 \\
\hline \multicolumn{7}{|l|}{ High-fat dairy } \\
\hline Median intake (g/d) & 27 & & 67 & & 182 & \\
\hline No. of subjects/cases & 1378/92 & & $1389 / 84$ & & $1419 / 97$ & \\
\hline Model $1^{*}$ & Ref & 0.89 & $0.66,1.20$ & 1.12 & $0.84,1.50$ & 0.43 \\
\hline Model $2 \dagger$ & Ref & 0.93 & $0.69,1.25$ & $1 \cdot 15$ & $0.86,1.54$ & 0.34 \\
\hline Model $3 \ddagger$ & Ref & 0.96 & $0.71,1.32$ & 1.23 & $0.91,1.67$ & 0.17 \\
\hline \multicolumn{7}{|l|}{ Low-fat dairy } \\
\hline Median intake $(\mathrm{g} / \mathrm{d})$ & 28 & & 294 & & 458 & \\
\hline No. of subjects/cases & $1403 / 98$ & & $1385 / 81$ & & $1398 / 94$ & \\
\hline Model $1^{*}$ & Ref & 0.83 & $0.62,1 \cdot 12$ & 0.91 & $0.69,1 \cdot 22$ & 0.54 \\
\hline Model $2 \dagger$ & Ref & 0.83 & $0.62,1.12$ & 0.93 & $0.70,1.25$ & 0.64 \\
\hline Model $3 \ddagger$ & Ref & 0.85 & $0.63,1.14$ & 0.98 & $0.73,1.31$ & 0.88 \\
\hline \multicolumn{7}{|l|}{ Total milk } \\
\hline Median intake (ml/d) & 147 & & 294 & & 441 & \\
\hline No. of subjects/cases & $1397 / 97$ & & 1379/92 & & $1410 / 84$ & \\
\hline Model $1^{*}$ & Ref & 0.95 & $0.71,1.26$ & 0.88 & $0.65,1.18$ & 0.39 \\
\hline Model $2 \dagger$ & Ref & 1.01 & $0.76,1.35$ & 0.90 & $0.66,1.21$ & 0.48 \\
\hline Model 3ł & Ref & 1.04 & $0.78,1.39$ & 0.97 & $0.71,1.32$ & 0.86 \\
\hline \multicolumn{7}{|l|}{ Fermented dairy } \\
\hline Median intake (g/d) & 17 & & 40 & & 105 & \\
\hline No. of subjects/cases & $1377 / 91$ & & $1385 / 87$ & & $1424 / 95$ & \\
\hline Model $1^{*}$ & Ref & 0.99 & $0.73,1.32$ & $1 \cdot 11$ & $0.83,1.48$ & 0.50 \\
\hline Model $2 \dagger$ & Ref & 1.00 & $0.74,1.34$ & $1 \cdot 12$ & $0.84,1.50$ & 0.45 \\
\hline Model 3‡ & Ref & 1.04 & $0.76,1.40$ & $1 \cdot 17$ & $0.87,1.58$ & 0.31 \\
\hline \multicolumn{7}{|l|}{ Yogurt } \\
\hline Median intake (g/d) & 0 & & 21 & & 117 & \\
\hline No. of subjects/cases & $1395 / 95$ & & $1361 / 85$ & & $1430 / 93$ & \\
\hline Model $1^{*}$ & Ref & 0.86 & $0.64,1.15$ & 0.91 & $0.68,1.21$ & 0.52 \\
\hline Model $2 \dagger$ & Ref & 0.92 & $0.68,1.23$ & 1.02 & $0.76,1.37$ & 0.91 \\
\hline Model 3‡ & Ref & 0.93 & $0.69,1 \cdot 27$ & 1.04 & $0.77,1.42$ & 0.77 \\
\hline \multicolumn{7}{|l|}{ Cheese } \\
\hline Median intake (g/d) & 6 & & 17 & & 31 & \\
\hline No. of subjects/cases & $1391 / 86$ & & $1393 / 97$ & & $1402 / 90$ & \\
\hline Model $1^{*}$ & Ref & $1 \cdot 17$ & $0.87,1.57$ & 1.24 & $0.92,1.67$ & $0 \cdot 16$ \\
\hline Model $2 \dagger$ & Ref & $1 \cdot 11$ & $0.83,1.49$ & $1 \cdot 14$ & $0.85,1.54$ & 0.38 \\
\hline Model 3‡ & Ref & $1 \cdot 15$ & $0.85,1.56$ & $1 \cdot 20$ & $0.88,1.64$ & 0.25 \\
\hline
\end{tabular}

Ref, reference.

${ }^{\star}$ Model 1: adjusted for age, ethnicity and employment grade.

† Model 2: model 1+smoking, alcohol intake, BMI, physical activity and family history of CHD/hypertension.

¥Model 3: model 2 + fruit and vegetables, bread, meat, fish, coffee, tea and total energy intake.

mortality (HR $1 \cdot 01$ per SD, 95\% CI $0 \cdot 88,1 \cdot 16$ ). For yogurt, a borderline inverse association was found (HR 0.88 per SD, $95 \%$ CI $0.74,1.02$ ).

Additional adjustments for changes in BMI during the follow-up did not alter any of the results for all-cause mortality (data not shown).

\section{Post hoc analyses}

Total dairy intake was no longer associated with all-cause mortality after excluding fermented dairy consumption from this group (HR 1.01, 95\% CI 0.72, 1.42 in the highest tertile).
Fermented dairy intake was inversely associated with allcause mortality but not with diabetes and CHD. In a post hoc analysis, we further examined the associations with CVD ( $n$ 53) and cancer mortality ( $n$ 126). For fatal CVD, the HR was $0.69(95 \%$ CI $0.35,1.36$ model $3, P$ for trend $=0.28)$ in the highest $v$. lowest tertile. For cancer mortality, the HR was $0.59(95 \%$ CI $0.39,0.91)$ in the highest $v$. lowest tertile (model 3, $P$ for trend $=0 \cdot 01$ ).

The effect of energy misreporting was assessed. We had 992 under-reporters, 2889 acceptable reporters and 173 overreporters. Exclusion of under- and/or over-reporters from the analysis did not alter the results of Tables 2-4. 
Table 3. Association between dairy intake and the 10-year risk of fatal and non-fatal CHD in 4255 participants of the Whitehall II study

(Hazard ratios and $95 \%$ confidence intervals)

\begin{tabular}{|c|c|c|c|c|c|c|}
\hline & \multicolumn{6}{|c|}{ Tertiles of sex- and energy-adjusted intake } \\
\hline & \multirow{2}{*}{$\frac{1}{\text { Hazard ratio }}$} & \multicolumn{2}{|c|}{2} & \multicolumn{2}{|c|}{3} & \multirow[b]{2}{*}{$P$ for trend } \\
\hline & & Hazard ratio & $95 \% \mathrm{Cl}$ & Hazard ratio & $95 \% \mathrm{Cl}$ & \\
\hline \multicolumn{7}{|l|}{ Total dairy intake } \\
\hline Median intake (g/d) & 246 & & 371 & & 575 & \\
\hline No. of subjects/cases & $1413 / 112$ & & $1403 / 112$ & & $1439 / 99$ & \\
\hline Model $1^{*}$ & Ref & 0.95 & $0.73,1.23$ & 0.83 & $0.64,1.09$ & 0.19 \\
\hline Model $2 \dagger$ & Ref & 0.98 & $0.75,1.27$ & 0.87 & $0.66,1.15$ & 0.33 \\
\hline Model $3 \ddagger$ & Ref & 1.03 & $0.78,1.35$ & 0.91 & $0.68,1.22$ & 0.53 \\
\hline \multicolumn{7}{|l|}{ High-fat dairy } \\
\hline Median intake (g/d) & 27 & & 67 & & 182 & \\
\hline No. of subjects/cases & $1394 / 111$ & & $1411 / 107$ & & $1450 / 105$ & \\
\hline Model $1^{*}$ & Ref & 0.95 & $0.73,1.25$ & 0.93 & $0.71,1.22$ & 0.60 \\
\hline Model $2 \dagger$ & Ref & 0.99 & $0.76,1.29$ & 0.96 & $0.73,1.26$ & 0.77 \\
\hline Model 3‡ & Ref & 1.06 & $0.80,1.39$ & 1.02 & $0.77,1.34$ & 0.91 \\
\hline \multicolumn{7}{|l|}{ Low-fat dairy } \\
\hline Median intake (g/d) & 28 & & 294 & & 458 & \\
\hline No. of subjects/cases & $1445 / 123$ & & 1399/92 & & $1411 / 108$ & \\
\hline Model $1^{*}$ & Ref & 0.77 & $0.59,1.02$ & 0.86 & $0.66,1.11$ & 0.23 \\
\hline Model $2 \dagger$ & Ref & 0.78 & $0.59,1.02$ & $0 \cdot 87$ & $0.67,1.13$ & 0.28 \\
\hline Model 3ł & Ref & 0.79 & $0.60,1.04$ & 0.87 & $0.67,1.14$ & 0.31 \\
\hline \multicolumn{7}{|l|}{ Total milk } \\
\hline Median intake $(\mathrm{ml} / \mathrm{d})$ & 147 & & 294 & & 441 & \\
\hline No. of subjects/cases & $1416 / 116$ & & $1400 / 96$ & & $1439 / 111$ & \\
\hline Model $1^{*}$ & Ref & 0.81 & $0.62,1.06$ & 0.88 & $0.67,1.14$ & 0.33 \\
\hline Model $2 \dagger$ & Ref & 0.83 & $0.63,1.09$ & 0.92 & $0.70,1.19$ & 0.52 \\
\hline Model 3‡ & Ref & 0.85 & $0.64,1 \cdot 12$ & 0.93 & $0.71,1.23$ & 0.62 \\
\hline \multicolumn{7}{|l|}{ Fermented dairy } \\
\hline Median intake (g/d) & 17 & & 40 & & 105 & \\
\hline No. of subjects/cases & $1390 / 110$ & & $1421 / 113$ & & $1444 / 100$ & \\
\hline Model $1^{*}$ & Ref & 1.02 & $0.78,1.33$ & 0.92 & $0.70,1.21$ & 0.54 \\
\hline Model $2 \dagger$ & Ref & 1.04 & $0.80,1.35$ & 0.92 & $0.70,1.21$ & 0.57 \\
\hline Model 3‡ & Ref & $1 \cdot 10$ & $0.84,1.44$ & 0.97 & $0.73,1.28$ & 0.83 \\
\hline \multicolumn{7}{|l|}{ Yogurt } \\
\hline Median intake $(\mathrm{g} / \mathrm{d})$ & 0 & & 21 & & 117 & \\
\hline No. of subjects/cases & $1420 / 105$ & & $1396 / 106$ & & $1439 / 112$ & \\
\hline Model $1^{\star}$ & Ref & 1.06 & $0.81,1.39$ & $1 \cdot 10$ & $0.84,1.45$ & 0.47 \\
\hline Model $2 \dagger$ & Ref & $1 \cdot 12$ & $0.85,1.47$ & $1 \cdot 18$ & $0.90,1.55$ & 0.24 \\
\hline Model 3‡ & Ref & $1 \cdot 18$ & $0.90,1.56$ & 1.23 & $0.93,1.63$ & 0.15 \\
\hline \multicolumn{7}{|l|}{ Cheese } \\
\hline Median intake $(\mathrm{g} / \mathrm{d})$ & 6 & & 17 & & 31 & \\
\hline No. of subjects/cases & $1401 / 118$ & & $1424 / 115$ & & $1430 / 90$ & \\
\hline Model $1^{*}$ & Ref & 0.98 & $0.76,1.27$ & 0.78 & $0.59,1.03$ & 0.09 \\
\hline Model $2 \dagger$ & Ref & 0.97 & $0.75,1.26$ & 0.77 & $0.58,1.02$ & 0.07 \\
\hline Model $3 \ddagger$ & Ref & 1.02 & $0.78,1.33$ & 0.82 & $0.61,1.09$ & $0 \cdot 17$ \\
\hline
\end{tabular}

Ref, reference.

* Model 1: adjusted for age, ethnicity and employment grade.

† Model 2: model 1+smoking, alcohol intake, BMI, physical activity and family history of CHD/hypertension.

¥ Model 3: model 2 + fruit and vegetables, bread, meat, fish, coffee, tea and total energy intake.

\section{Discussion}

The present prospective cohort study in 4000 adult men and women showed no consistent associations of total dairy and types of dairy food intake with incident type 2 diabetes, CHD or all-cause mortality.

A total of 10308 subjects were enrolled in the Whitehall II study (phase I). A FFQ that contained information on different types of dairy products was introduced 10 years later (phase 5) and completed by 5088 subjects (49\%). These subjects smoked less and had a lower BMI, higher employment grade and lower blood pressure compared with those not included in the present analysis. Whitehall II study participants are office-based civil servants and therefore not fully representative of the total UK population. However, we consider it unlikely that the relationship between dairy product intakes and the outcomes in the present study would differ from that in the general population.

We used a validated $\mathrm{FFQ}^{(24)}$ that ranked individuals sufficiently for $\mathrm{Ca}$ when compared with $7 \mathrm{~d}$ food diaries and biomarkers with energy-adjusted Spearman's correlations of $0 \cdot 44-0.48^{(22)}$. A disadvantage of the FFQ is that it is memory-based, which could lead to under- or over-reporting of food intake ${ }^{(28)}$. We did not update dietary data during the follow-up, which is a limitation of the present analysis. 
Table 4. Association between dairy intake and the 12-year risk of all-cause mortality in 4522 participants of the Whitehall II study (Hazard ratios and $95 \%$ confidence intervals)

\begin{tabular}{|c|c|c|c|c|c|c|}
\hline & \multicolumn{6}{|c|}{ Tertiles of sex- and energy-adjusted dairy intake } \\
\hline & \multirow{2}{*}{$\frac{1}{\text { Hazard ratio }}$} & \multicolumn{2}{|c|}{2} & \multicolumn{2}{|c|}{3} & \multirow[b]{2}{*}{$P$ for trend } \\
\hline & & Hazard ratio & $95 \% \mathrm{Cl}$ & Hazard ratio & $95 \% \mathrm{Cl}$ & \\
\hline \multicolumn{7}{|l|}{ Total dairy intake } \\
\hline Median intake (g/d) & 246 & & 371 & & 575 & \\
\hline No. of subjects/cases & $1504 / 104$ & & $1501 / 60$ & & $1517 / 73$ & \\
\hline Model $1^{*}$ & Ref & 0.53 & $0.39,0.73$ & 0.64 & $0.47,0.87$ & $<0.01$ \\
\hline Model $2 \dagger$ & Ref & 0.56 & $0.41,0.78$ & 0.69 & $0.51,0.93$ & 0.01 \\
\hline Model 3ł & Ref & 0.57 & $0.41,0.79$ & 0.72 & $0.52,0.99$ & 0.04 \\
\hline \multicolumn{7}{|l|}{ High fat dairy } \\
\hline Median intake $(\mathrm{g} / \mathrm{d})$ & 27 & & 67 & & 182 & \\
\hline No. of subjects/cases & $1506 / 92$ & & $1499 / 70$ & & $1517 / 75$ & \\
\hline Model $1^{*}$ & Ref & 0.75 & $0.55,1.03$ & 0.82 & $0.60,1.12$ & 0.20 \\
\hline Model $2 \dagger$ & Ref & 0.76 & $0.55,1.04$ & 0.83 & $0.61,1.13$ & 0.22 \\
\hline Model 3ł & Ref & 0.74 & $0.53,1.02$ & 0.83 & $0.60,1 \cdot 14$ & 0.25 \\
\hline \multicolumn{7}{|l|}{ Low fat dairy } \\
\hline Median intake (g/d) & 28 & & 294 & & 458 & \\
\hline No. of subjects/cases & $1512 / 90$ & & $1501 / 77$ & & $1509 / 70$ & \\
\hline Model $1^{*}$ & Ref & 0.83 & $0.61,1.13$ & 0.71 & $0.52,0.97$ & 0.03 \\
\hline Model 2† & Ref & 0.90 & $0.66,1.22$ & 0.79 & $0.57,1.08$ & 0.14 \\
\hline Model 3‡ & Ref & 0.90 & $0.66,1.23$ & 0.84 & $0.60,1 \cdot 16$ & 0.28 \\
\hline \multicolumn{7}{|l|}{ Total milk } \\
\hline Median intake (ml/d) & 147 & & 294 & & 441 & \\
\hline No. of subjects/cases & $1502 / 86$ & & $1501 / 80$ & & $1519 / 71$ & \\
\hline Model $1^{*}$ & Ref & 0.90 & $0.66,1.22$ & 0.77 & $0.56,1.05$ & 0.10 \\
\hline Model $2 \dagger$ & Ref & 0.93 & $0.68,1.27$ & 0.80 & $0.58,1.11$ & 0.18 \\
\hline Model 3‡ & Ref & 0.98 & $0.72,1.34$ & 0.89 & $0.64,1.25$ & 0.51 \\
\hline \multicolumn{7}{|l|}{ Fermented dairy } \\
\hline Median intake $(\mathrm{g} / \mathrm{d})$ & 17 & & 40 & & 105 & \\
\hline No. of subjects/cases & $1498 / 100$ & & $1496 / 70$ & & $1528 / 67$ & \\
\hline Model $1^{*}$ & Ref & 0.69 & $0.51,0.93$ & 0.66 & $0.48,0.90$ & $<0.01$ \\
\hline Model $2 \dagger$ & Ref & 0.69 & $0.51,0.94$ & 0.68 & $0.50,0.93$ & 0.01 \\
\hline Model $3 \ddagger$ & Ref & 0.66 & $0.48,0.91$ & 0.65 & $0.47,0.90$ & $<0.01$ \\
\hline \multicolumn{7}{|l|}{ Yogurt } \\
\hline Median intake (g/d) & 0 & & 21 & & 117 & \\
\hline No. of subjects/cases & $1497 / 84$ & & $1494 / 92$ & & $1531 / 61$ & \\
\hline Model $1^{*}$ & Ref & 1.07 & $0.80,1.45$ & 0.67 & $0.48,0.94$ & 0.02 \\
\hline Model $2 \dagger$ & Ref & $1 \cdot 15$ & $0.85,1.55$ & 0.76 & $0.55,1.07$ & 0.14 \\
\hline Model 3ł & Ref & $1 \cdot 13$ & $0.83,1.53$ & 0.74 & $0.53,1.05$ & $0 \cdot 10$ \\
\hline \multicolumn{7}{|l|}{ Cheese } \\
\hline Median intake $(\mathrm{g} / \mathrm{d})$ & 6 & & 17 & & 31 & \\
\hline No. of subjects/cases & $1510 / 83$ & & $1509 / 73$ & & $1503 / 81$ & \\
\hline Model $1^{*}$ & Ref & 0.93 & $0.68,1.27$ & 1.05 & $0.77,1.43$ & 0.76 \\
\hline Model $2 \dagger$ & Ref & 0.91 & $0.67,1.25$ & 1.01 & $0.74,1.37$ & 0.96 \\
\hline Model $3 \ddagger$ & Ref & 0.90 & $0.65,1.25$ & 1.00 & $0.72,1.37$ & 0.99 \\
\hline
\end{tabular}

Ref, reference.

${ }^{*}$ Model 1: adjusted for age, ethnicity and employment grade.

† Model 2: model $1+$ smoking, alcohol intake, BMI, physical activity and family history of CHD/hypertension.

$\ddagger$ Model 3: model $2+$ fruit and vegetables, bread, meat, fish, coffee, tea and total energy intake.

Although correction for energy misreporting and changes in BMI during the follow-up did not alter the present results, we cannot exclude the possibility that misclassification of subjects for dairy intake biased the results from the present study towards the null. Several objective biomarkers for dairy fat intake have been proposed, which showed conflicting relationships with $\mathrm{CHD}^{(29,30)}$. We had no biomarker data available in the Whitehall II study to perform such analyses.

There were no statistically significant associations between dairy food intake and incident type 2 diabetes. Previous meta-analyses $^{(9,11,12)}$ and prospective cohort studies ${ }^{(31-36)}$ reported inverse associations between low-fat dairy intake and incident type 2 diabetes. In the most recent meta-analyses, inverse associations of total dairy intake and diabetes were found in women, but not in men ${ }^{(12)}$. In the UK Caerphilly cohort study, there was no significant association between milk consumption and incident diabetes in men who had kept $7 \mathrm{~d}$ weighed intake records ${ }^{(19)}$. Our cohort consisted of $72 \%$ male participants, and we did not find an association with diabetes, which is in line with previous studies showing no relationship in men ${ }^{(12,19)}$. We have no likely explanation why women would be more responsive to dairy intake than men with respect to diabetes.

In the present study, no associations were found between dairy food intake and incident CHD. This finding was in accordance with a recent meta-analysis, which also reported 
no associations between milk consumption and incident CHD on the basis of six prospective cohort studies (HR 1.00, $95 \% \mathrm{CI}$ $0.96,1.04)^{(10)}$. In another meta-analysis of nine prospective studies, an inverse association between milk (and dairy food) and CHD has been reported (HR 0.92, 95\% CI 0.80, 0.99 for the highest relative to lowest intake) ${ }^{(9)}$, but the results were attenuated when types of milk were taken into account for one large study contributing to this meta-analysis ${ }^{(14)}$.

We found an inverse association between fermented dairy intake and all-cause mortality, but not with diabetes and CHD. This appeared to be due to yogurt rather than cheese intake, although this finding needs confirmation in further studies. In a previous Dutch study on 120852 men and women followed for 10 years, fermented full-fat milk was also inversely related to all-cause mortality, with relative risks of 0.91 (95\% CI 0.86, 0.97) in men and 0.92 (95\% CI 0.85, 1.00) in women per intake of $100 \mathrm{~g} / \mathrm{d}$. The group of fermented dairy in that study, however, contained other products (full-fat yogurt, quark, fresh cheese and sour cream) different from that used in the present study (soft and hard cheese and yogurt), which makes these studies not fully comparable ${ }^{(37)}$. There is some evidence that vitamin $\mathrm{K}_{2}$ present in fermented dairy products plays a role in apoptosis and cell-cycle arrest influencing carcinogenesis ${ }^{(38,39)}$, which may explain the associations with cancer ${ }^{(40)}$ in the present post hoc analyses. On the other hand, fermented dairy consumption could be a marker of healthy food choices in general and residual confounding cannot be ruled out completely.

In conclusion, total dairy and types of dairy food consumption were not associated with diabetes, CHD or all-cause mortality in the present prospective cohort study of Londonbased civil servants. We observed an inverse relationship of fermented dairy products with all-cause mortality, which needs confirmation in further studies.

\section{Acknowledgements}

We thank all participating civil service departments and their welfare, personnel, and establishment officers; the Occupational Health and Safety Agency; the Council of Civil Service Unions; all participating civil servants in the Whitehall II study; and all members of the Whitehall II study team. The Whitehall II study was supported by grants from the Medical Research Council (G0902037), the British Heart Foundation (RG/07/ 008/23674), the Stroke Association, the National Heart Lung and Blood Institute (5RO1 HL036310), the National Institute on Aging (5RO1AG13196) and the Agency for Health Care Policy Research (5RO1AG034454). The contributions of the authors were as follows: S. S. S.-M. proposed the idea and wrote the paper; G. M. prepared the dietary data, analysed the data and edited the writing; L. V. made all tables and edited the writing; J. M. G. edited the writing; E. J. B. is the principal investigator of the study, contributed to the data and edited the writing. Conflicts of interests: S. S. S.-M., L. V. and J. M. G. obtained an unrestricted grant from the Dutch Dairy Association (NZO) to carry out meta-analyses on the association between dairy products and CVD. G. M. was funded by the British Heart Foundation and E. J. B. was supported by the British Heart Foundation and the Stroke Association. Role of the sponsor: the sponsors were not involved in the conduct and writing of the manuscript.

\section{References}

1. Mackay J \& Mensah G (2004) WHO - The Atlas of Heart Disease and Stroke 2004, 1st ed. Geneva: World Health Organization. http://www.amazon.com/Atlas-HeartDisease-Stroke/dp/9241562765\#reader_9241562765

2. Sarwar N, Gao P, Seshasai SR, et al. (2010) Diabetes mellitus, fasting blood glucose concentration, and risk of vascular disease: a collaborative meta-analysis of 102 prospective studies. Lancet 375, 2215-2222.

3. Stampfer MJ, Hu FB, Manson JE, et al. (2000) Primary prevention of coronary heart disease in women through diet and lifestyle. $N$ Engl J Med 343, 16-22.

4. Hu FB, Manson JE, Stampfer MJ, et al. (2001) Diet, lifestyle, and the risk of type 2 diabetes mellitus in women. $N$ Engl $J$ Med 345, 790-797.

5. Yusuf S, Hawken S, Ounpuu S, et al. (2004) Effect of potentially modifiable risk factors associated with myocardial infarction in 52 countries (the INTERHEART study): casecontrol study. Lancet 364, 937-952.

6. Van Horn L \& Dietary Guidelines Advisory Committee (2010) Development of the 2010 US Dietary Guidelines Advisory Committee Report: perspectives from a registered dietitian. J Am Diet Assoc 110, 1638-1645.

7. Graham I, Atar D, Borch-Johnsen K, et al. (2007) European guidelines on cardiovascular disease prevention in clinical practice: executive summary. Eur Heart J 28, 2375-2414.

8. Lichtenstein AH, Appel LJ, Brands M, et al. (2006) Diet and lifestyle recommendations revision 2006: a scientific statement from the American Heart Association Nutrition Committee. Circulation 114, 82-96.

9. Elwood PC, Pickering JE, Givens DI, et al. (2010) The consumption of milk and dairy foods and the incidence of vascular disease and diabetes: an overview of the evidence. Lipids 45, 925-939.

10. Soedamah-Muthu SS, Ding EL, Al-Delaimy WK, et al. (2011) Milk and dairy consumption and incidence of cardiovascular diseases and all-cause mortality: dose-response metaanalysis of prospective cohort studies. Am J Clin Nutr 93, $158-171$.

11. Pittas AG, Lau J, Hu FB, et al. (2007) The role of vitamin $\mathrm{D}$ and calcium in type 2 diabetes. A systematic review and meta-analysis. J Clin Endocrinol Metab 92 2017-2029.

12. Tong X, Dong JY, Wu ZW, et al. (2011) Dairy consumption and risk of type 2 diabetes mellitus: a meta-analysis of cohort studies. Eur J Clin Nutr 65, 1027-1031.

13. Al-Delaimy WK, Rimm E, Willett WC, et al. (2003) A prospective study of calcium intake from diet and supplements and risk of ischemic heart disease among men. Am J Clin Nutr 77, 814-818.

14. Hu FB, Stampfer MJ, Manson JE, et al. (1999) Dietary saturated fats and their food sources in relation to the risk of coronary heart disease in women. Am J Clin Nutr 70, 1001-1008.

15. Bostick RM, Kushi LH, Wu Y, et al. (1999) Relation of calcium, vitamin D, and dairy food intake to ischemic heart disease mortality among postmenopausal women. Am J Epidemiol 149, 151-161. 
16. Liu S, Choi HK, Ford E, et al. (2006) A prospective study of dairy intake and the risk of type 2 diabetes in women. Diabetes Care 29, 1579-1584.

17. Choi HK, Willett WC, Stampfer MJ, et al. (2005) Dairy consumption and risk of type 2 diabetes mellitus in men: a prospective study. Arch Intern Med 165, 997-1003.

18. Elwood PC, Pickering JE, Fehily AM, et al. (2004) Milk drinking, ischaemic heart disease and ischaemic stroke I. Evidence from the Caerphilly cohort. Eur J Clin Nutr 58, 711-717.

19. Elwood PC, Pickering JE \& Fehily AM (2007) Milk and dairy consumption, diabetes and the metabolic syndrome: the Caerphilly prospective study. J Epidemiol Comm Health 61, 695-698.

20. Ness AR, Smith GD \& Hart C (2001) Milk, coronary heart disease and mortality. J Epidemiol Comm Health 55, 379-382.

21. Marmot M \& Brunner E (2005) Cohort profile: the Whitehall II study. Int J Epidemiol 34, 251-256.

22. Brunner EJ, Stallone D, Juneja M, et al. (2001) Dietary assessment in Whitehall II: comparison of $7 \mathrm{~d}$ diet and food-frequency questionnaire and validity against biomarkers. BrJ Nutr 86, 405-414.

23. Rose GA (1962) The diagnosis of ischaemic heart pain and intermittent claudication in field surveys. Bull World Health Organ 27, 645-658.

24. Willett WC (1998) Nutritional Epidemiology. New York: Oxford University Press.

25. Department of Health (1991) Dietary Reference Values for Food and Energy and Nutrients for the United Kingdom. In Report of the Panel on Dietary Reference Values of the Committee on Medical Aspects of Food Policy. London: The Stationery Office.

26. Goldberg GR, Black AE, Jebb SA, et al. (1991) Critical evaluation of energy intake data using fundamental principles of energy physiology: 1 . Derivation of cut-off limits to identify under-recording. Eur J Clin Nutr 45, 569-581.

27. Black AE (2000) Critical evaluation of energy intake using the Goldberg cut-off for energy intake:basal metabolic rate. A practical guide to its calculation, use and limitations. Int J Obes Relat Metab Disord 24, 1119-1130.

28. van Staveren WA \& Ocke MC (2001) Estimation of dietary intake. In Present Knowledge in Nutrition, pp. 605-616 [BA Bowman and RM Russell, editors]. Washington, DC: International Life Sciences Institute (ILSI) Press.
29. Sun Q, Ma J, Campos H, et al. (2007) Plasma and erythrocyte biomarkers of dairy fat intake and risk of ischemic heart disease. Am J Clin Nutr 86, 929-937.

30. Warensjo E, Smedman A, Stegmayr B, et al. (2009) Stroke and plasma markers of milk fat intake - a prospective nested case-control study. Nutr J 8, 21.

31. Fumeron F, Lamri A, Abi Khalil C, et al. (2011) Dairy consumption and the incidence of hyperglycemia and the metabolic syndrome: results from a French prospective study, Data from the Epidemiological Study on the Insulin Resistance Syndrome (DESIR). Diabetes Care 34, 813-817.

32. Fuhrman BJ, Smit E, Crespo CJ, et al. (2009) Coffee intake and risk of incident diabetes in Puerto Rican men: results from the Puerto Rico Heart Health Program. Public Health Nutr 12, 842-848.

33. Montonen J, Jarvinen R, Heliovaara M, et al. (2005) Food consumption and the incidence of type II diabetes mellitus. Eur J Clin Nutr 59, 441-448.

34. Nettleton JA, Steffen LM, Ni H, et al. (2008) Dietary patterns and risk of incident type 2 diabetes in the Multi-Ethnic Study of Atherosclerosis (MESA). Diabetes Care 31, 1777-1782.

35. Malik VS, Sun Q, van Dam RM, et al. (2011) Adolescent dairy product consumption and risk of type 2 diabetes in middleaged women. Am J Clin Nutr 94, 854-861.

36. Margolis KL, Wei F, de Boer IH, et al. (2011) A diet high in low-fat dairy products lowers diabetes risk in postmenopausal women. J Nutr 141, 1969-1974

37. Goldbohm RA, Chorus AM, Galindo Garre F, et al. (2011) Dairy consumption and 10-y total and cardiovascular mortality: a prospective cohort study in the Netherlands. $A m J$ Clin Nutr 93, 615-627.

38. Matsumoto K, Okano J, Nagahara T, et al. (2006) Apoptosis of liver cancer cells by vitamin $\mathrm{K}_{2}$ and enhancement by MEK inhibition. Int J Oncol 29, 1501-1508.

39. Habu D, Shiomi S, Tamori A, et al. (2004) Role of vitamin $\mathrm{K}_{2}$ in the development of hepatocellular carcinoma in women with viral cirrhosis of the liver. JAMA 292, 358-361.

40. Nimptsch K, Rohrmann S, Kaaks R, et al. (2010) Dietary vitamin $\mathrm{K}$ intake in relation to cancer incidence and mortality: results from the Heidelberg cohort of the European Prospective Investigation into Cancer and Nutrition (EPIC-Heidelberg). Am J Clin Nutr 91, 1348-1358. 